\title{
ANTI HEPATITIS C VIRAL DRUGS REMDESIVIR AND UPRIFOSBUVIR DERIVATIVES ARE BETTER INHIBITORS OF SARS COV2 RNA-DEPENDENT RNA POLYMERASE DETERMINED BY DOCKING.
}

\author{
Gudipati Pavan Kumar, \\ Independent Researcher, \\ Pragathi nagar, Hyderabad. \\ Telangana, India
}

\author{
Shyamasri Biswas, \\ USA Prime Biotech LLC \\ Gainesville, FL-32608
}

\author{
Pankaj Goyal, \\ Department of Biotechnology \\ School of Life Sciences \\ Central University of Rajasthan \\ Rajasthan, India
}

Abstract: SARS Cov2 RNA-dependent RNA polymerase (RdRp) is an enzyme that catalyzes the synthesis and replication of viral RNA from an RNA template. Our starting model for this study was (SARS-Cov-2) cryo-EM structure published recently (PDB ID 6M71). We have used docking studies to find a better inhibitor for the enzyme that can be used in the treatment of SARS-CoV2 infections. Recently, several inhibitors like Sofosbuvir, Ribavirin, and Remdesivir has been reported as strong inhibitors of this enzyme. Our results show an analogue of Remdesivir such as CHEMBL3120791 and analogue of Uprifosbuvir SCHEMBL20762917, SCHEMBL20733228 as better inhibitors than previously reported inhibitors of RNA-dependent RNA polymerase. Using Autodock Vina and Pyrx software for virtual screening of ligands, we found four higher efficiency compounds CHEMBL3120791, SCHEMBL20762917, SCHEMBL20733228 and Uprifosbuvir. The binding constant of these ligands were $\mathbf{- 9 . 5}$ (Kcal/mol), -8.3 (Kcal/mol), -8.3 (Kcal/mol), -8.6 (Kcal/mol), respectively when tested on SARS-COV-2 nsp12. Active site interactions with the potential drug molecule are with residues Lys47, Tyr129, Ser784, His133 and Ser709 for CHEMBL3120791, SCHEMBL20762917 and SCHEMBL20733228. These molecules can be used in the future drug development process in the treatment of SARS-Cov2 infection. The molecules reported here are already under clinical trial for the treatment of $\mathrm{HCV}$ (Hepatitis C Virus) infections, which is similar to SARS Cov2, as both are positive-sense RNA Viruses. We also investigated binding efficacy of these identified inhibitors against SARS spike protein for this, we used pdb files 2GHV (SARS spike protein receptor binding domain) and 5XLR (SARS CoV spike glycoprotein). In addition, 1P9U which is coronavirus main proteinase was also evaluated.
The compounds identified and reported here also showed better binding affinity towards these proteins.

Keywords: SARS Cov2, RNA-dependent RNA polymerase, RdRP, Docking, Drug Design, Hepatitis C Virus, Remdesivir, Uprifosbuvir, CHEMBL3120791, SCHEMBL20762917 SCHEMBL20733228, 6M71, 2GHV, 5XLR, 1P9U

\section{INTRODUCTION}

SARS CoV-2 virus that causes COVID-19 respiratory disease has emerged as one of the deadly pathogens of the $21^{\text {st }}$ century [1]. SARS CoV2 is an enveloped non segmented positive sense RNA coronavirus belonging to genus Betacoronavirus [2]. This genus also includes two other RNA viruses that has caused epidemics like Severe Acute Respiratory Syndrome (SARS) caused by SARS-CoV and Middle East Respiratory Syndrome (MERS) caused by MERS-CoV [3], [4]. Due to high affinity of the viral spike protein with host receptor, infection of SARS CoV-2 is known to increase exponentially thereby increasing human to human transmission [5].

RNA dependent RNA polymerase (RdRp) of SARS COV-2 is known to mediate replication of the viral genome and its propagation inside host cells [6]. The core component of RdRP is nsp12 (nonstructural protein) which has little activity but together with nsp7 and nsp8 can increase RdRP template binding and processivity rate [7], [8] RdRP is also the target of a class of antivirals like Remdesivir [9] that has come into spotlight recently as human clinical trials have shown promise in treatment of COVID-19. Remdesivir is a nucleotide analog and is a prodrug that is converted to active drug in triphosphate form inside cells [10], [11]. 


\section{International Journal of Engineering Applied Sciences and Technology, 2020 Vol. 5, Issue 3, ISSN No. 2455-2143, Pages 474-481 \\ Published Online July 2020 in IJEAST (http://www.ijeast.com)}

Angiotensin converting enzyme (ACE2) receptor has been identified as the entry point for SARS virus into host cells [12]. ACE2 is expressed in various organs and tissues namely lungs, cardiovascular system, gut, kidneys, central nervous system, and adipose tissue [13]. The spike protein of SARS virus has strong binding affinity for the ACE2 receptor. Although SARS CoV-2 receptor binding domain has close homology to most SARS virus, there are several amino acids that are different [14]. These differences in amino acid composition allow SARS CoV2 to bind to ACE2 with higher affinity thereby spreading the disease and enabling viral replication [15].

Apart from ACE2 receptor and SARS CoV2 RdRp, coronavirus main proteinase $\left(3 \mathrm{CL}{ }^{\text {pro }}\right.$ ) has also been reported as a potential drug target against SARS virus [16 - 18]. This proteinase is a major component of coronavirus replication complex and belongs to the cysteine protease family, it also plays a major role in processing polyproteins [19]. Inhibition of this proteinase function will hamper replication and proliferation of the virus [20].

In this report we have used docking studies with Remdesivir as well as its analogues and Ribavirin, Uprifosbuvir, Adafosbuvir and several other compounds to find the best inhibitor for RdRp. We identified a few compounds that had better efficacy not only towards RdRp but also can be used for inhibition of SARS main proteinase 3CLpro and SARS CoV2 spike glycoprotein. Thus the inhibitors identified in this docking study can be used as a broad spectrum inhibitor for number of target proteins present in SARS CoV2. We believe these results will enable us to design better drugs for the treatment of this deadly virus.

\section{MATERIAL \& METHODS}

\section{A. Protein}

Protein File: In this study, the structure of SARS CoV-2 RdRP (RNA-dependent RNA polymerase) was used as a starting model (PDB ID 6M71) [21 - 22]. The structure was obtained from the RCSB website with pdb ID 6M71. This is a $2.9 \AA$ resolution cryo EM structure consisting of 4 chains, which are A, B, C and D. In this structure A Chain is the SARS-Cov2 nsp12, B, D chains are SARS-Cov2 nsp8 and C Chain is SARS-COV-2 nsp7. Recent reports by Kirchdoerfer, R.N., Ward et.al indicates that all three non-structured proteins are assembled to form the RdRp enzyme [23].

\section{B. Chemical Data}

Chemical Data: The data for the inhibitors were collected from Pubchem [24] which includes various antiviral drugs such as Ribavirin, Uprifosbuvir, Remdesivir, Adafosbuvir, and their analogs. Remdesivir is a potential inhibitor for SARSCov-2 RNA-dependent RNA polymerase. Remdesivir interacts with active site residues Arg-555, Ser-549 and Asp-
618 of this RdRP protein [17]. Ribavirin is a synthetic nucleoside analog of ribofuranose with activity against hepatitis C virus and other RNA viruses [25 - 26], Uprifosbuvir is under investigation in clinical trial for Hepatitis C Virus (HCV) [27], Adafosbuvir also exhibits antiviral activity [28]. In order to find a better inhibitor that binds RdRp with better binding efficiency than Remdesivir, we selected thirty one compounds in our docking studies.

Table 1: Thirty one compounds used for this docking studies

\begin{tabular}{|c|c|c|}
\hline S.No & Pubchem ID & Chemical Name \\
\hline 1 & CID5064 [39] & ICN 1229 \\
\hline 2 & CID37542 [40] & Ribavirin \\
\hline 3 & CID100252 [41] & $\begin{array}{l}\text { Ribavirin } \\
\text { monophosphate }\end{array}$ \\
\hline 4 & CID122108[42] & Ribavirin 5'-triphosphate \\
\hline 5 & CID124970 [43] & Ribavirin 5'-diphosphate \\
\hline 6 & CID129235 [44] & Ribavirin 5'-sulfamate \\
\hline 7 & CID362949[45] & SCHEMBL6981526 \\
\hline 8 & CID451448 [46] & Ribavirin amidine \\
\hline 9 & CID451949 [47] & dd-ribavarin \\
\hline 10 & CID452722 [48] & 3'-Deoxyribavirin \\
\hline 11 & CID460516 [49] & Levovirin, L-Ribavirin \\
\hline 12 & CID6713992 [50] & Ribavirin E \\
\hline 13 & CID10220469 [51] & SCHEMBL1981630 \\
\hline 14 & CID11436477 [52] & alpha-Ribavirin \\
\hline 15 & CID40629571 [53] & SCHEMBL326516 \\
\hline 16 & CID54759694[54] & CHEMBL3120793 \\
\hline 17 & CID70989848 [55] & SCHEMBL13761348 \\
\hline 18 & CID76325303 [56] & CHEMBL3120791 \\
\hline 19 & CID90055716 [57] & Uprifosbuvir \\
\hline 20 & CID118596336 [58] & Adafosbuvir \\
\hline 21 & CID121304016 [59] & Remdesivir \\
\hline 22 & CID137465280[60] & SCHEMBL20705434 \\
\hline 23 & CID137490591 [61] & SCHEMBL20733226 \\
\hline 24 & CID137490593[62] & SCHEMBL20733228 \\
\hline 25 & CID137509756 [63] & SCHEMBL20754604 \\
\hline 26 & CID137517260 [64] & SCHEMBL20762917 \\
\hline 27 & CID137517361 [65] & SCHEMBL20763026 \\
\hline 28 & CID45375808[66] & Sofosbuvir \\
\hline 29 & CID6440764 [67] & Thymectacin \\
\hline 30 & CID3652 [68] & Hydroxychloroquine \\
\hline 31 & CID71826 [69] & Cletoquine \\
\hline
\end{tabular}

Table 1 shows Ribavirin, Uprifosbuvir, Adafosbuvir, Remdesivir, Sofosbuvir, Themetacin, Hydroxychloroquine, and related analogues of these molecules. These molecules were docked against protein structure 6M71 using PyRx and Autodock Vina. 


\section{International Journal of Engineering Applied Sciences and Technology, 2020 Vol. 5, Issue 3, ISSN No. 2455-2143, Pages 474-481 \\ Published Online July 2020 in IJEAST (http://www.ijeast.com)}

\section{Docking Studies}

We performed docking studies using two different strategies, first we excluded B, C and D chains and used only " $A$ " chain for docking and in the second iteration we used all 4 chains which is the complete enzyme complex. Recent reports indicate that nsp12(chain A) has low template binding and processivity rate by itself, for efficient binding and activity the whole enzyme complex with chain A, B, C \& D are required [7 - 8]. Hence, we also performed docking studies with the whole enzyme complex comprising of nsp12, nsp7 and nsp8. For Docking, we used Autodock [29], Autodock Vina [30] and PyRx [31]. Apart from selective ligands, we have used control, which are Sugar [70], Maltose [71], and Amino Sugar [72].

In order to investigate whether these inhibitors can also work with spike protein inhibition of SARS-CoV2 we downloaded pdb file for spike protein of SARS-CoV2. The pdb file used for this was $2 \mathrm{GHV}$ [32], which is receptor binding domain of SARS spike protein. We also performed docking studies using 5XLR (SARS-CoV2 spike glycoprotein) [33], 1P9U (Corona virus main proteinase 3CLpro ) [20].

\section{RESULTS AND DISCUSSION}

In this report we have performed docking studies with 31 different molecules that are Remdesivir analogues (Table 1). We have used Autodock, Autodock Vina, and PyRx virtual screening software. Our starting pdb was $6 \mathrm{M} 71$ which is RNA dependent RNA polymerase of SARS CoV-2.

Out of 31 compounds used for our docking studies we identified four compounds that produced better binding efficiency than Remdesivir particularly with chain A or nsp12 molecule alone. These compounds are CHEMBL3120791, SCHEMBL20733228,Uprifosbuvir and SCHEMBL20762917.

Our Rational behind using CHEMBL3120791 and SCHEMBL20733228 originates from the fact that these two compounds has been reported to exhibit antiviral activity against HCV (Hepatitis C Virus) genotype 1b [34]. In this study, human $\mathrm{HuH7}$ cells were used and when treated with these compounds the viral replication was inhibited after 3 days studied by luminescence assay. Previous studies have shown SCHEMBL20733228 and Uprifosbuvir exhibited antiviral activity against HCV infections [27], [35]. Most of these drugs are under clinical trials.

In our docking studies with chain A (SARS-COV-2 nsp12) better binding affinity was observed with four compounds identified as CHEMBL3120791, SCHEMBL20733228, Uprifosbuvir and SCHEMBL20762917. The respective binding energy for these compounds were: CHEMBL3120791
-9.5 Kcal/mol, SCHEMBL20733228 : $-8.3 \mathrm{Kcal} / \mathrm{mol}$, Uprifosbuvir -8.6 Kcal/mol and SCHEMBL20762917 with $8.3 \mathrm{Kcal} / \mathrm{mol}$. Remdesivir in comparison had much lower binding energy of $-6.8 \mathrm{kcal} / \mathrm{mol}$ (Table 2)

Table 2: Binding Energy of ligands on "A" Chain SARSCOV-2 nsp12 Only. Controls: Sugar -6.8, Maltose -6.8 and Amino sugar with $-5.6 \mathrm{Kcal} / \mathrm{mol}$.

\begin{tabular}{|l|l|l|}
\hline $\begin{array}{l}\text { Ligand } \\
\text { (Pubchem Id) }\end{array}$ & $\begin{array}{l}\text { Binding } \\
\text { Energy } \\
(\text { Kcal/mol) }\end{array}$ & Chemical Name \\
\hline CID76325303 & -9.5 & CHEMBL3120791 \\
\hline CID137490593 & -8.3 & SCHEMBL20733228 \\
\hline CID90055716 & -8.6 & Uprifosbuvir \\
\hline CID137517260 & -8.3 & SCHEMBL20762917 \\
\hline CID 45375808 & -8.0 & Sofosbuvir \\
\hline CID137509756 & -8.3 & SCHEMBL20754604 \\
\hline CID137517361 & -8.8 & SCHEMBL20763026 \\
\hline CID121304016 & -6.8 & Remdesivir \\
\hline
\end{tabular}

Table 3: Binding Energy of ligands on All Chains, which Includes nsp12, nsp8, nsp7. Controls: Sugar -6.8, Maltose 6.3 and Amino sugar with $-5.4 \mathrm{Kcal} / \mathrm{mol}$

\begin{tabular}{|l|l|l|}
\hline $\begin{array}{l}\text { Ligand } \\
\text { (Pubchem Id) }\end{array}$ & $\begin{array}{l}\text { Binding } \\
\text { Energy } \\
\text { (Kcal/mol) }\end{array}$ & Chemical Name \\
\hline CID90055716 & -8.8 & Uprifosbuvir \\
\hline CID76325303 & -8.5 & CHEMBL3120791 \\
\hline CID137517260 & -8.3 & SCHEMBL20762917 \\
\hline CID121304016 & -8.2 & Remdesivir \\
\hline CID45375808 & -7.8 & Sofosbuvir \\
\hline CID137490591 & -7.7 & SCHEMBL20733226 \\
\hline CID137490593 & -7.7 & SCHEMBL20733228 \\
\hline CID137509756 & -7.7 & SCHEMBL20754604 \\
\hline CID118596336 & -7.6 & Adafosbuvir \\
\hline
\end{tabular}

Docking results with all four chains which include nsp12, nsp7 and nsp8, yielded the following binding energies: Uprifosbuvir: -8.8 Kcal/mol, CHEMBL3120791: -8.5 Kcal/moll, SCHEMBL20762917: -8.3 Kcal/mol. The binding energy with Remdesivir is $-8.2 \mathrm{kcal} / \mathrm{mol}$, which is close to the compound studied here. (Table 3)

From our docking studies, with the better binding energy compounds, active residues identified were Lys47, Ser784, Ser709, Tyr129, His133, Thr141 using Ligplus+ (Fig. 1) (Table 4)

Fig. 1. CHEMBL3120791 (CID76325303) with 6M71 using LigPlus+ $($ unk0 $=$ CID76325303 $)$ 


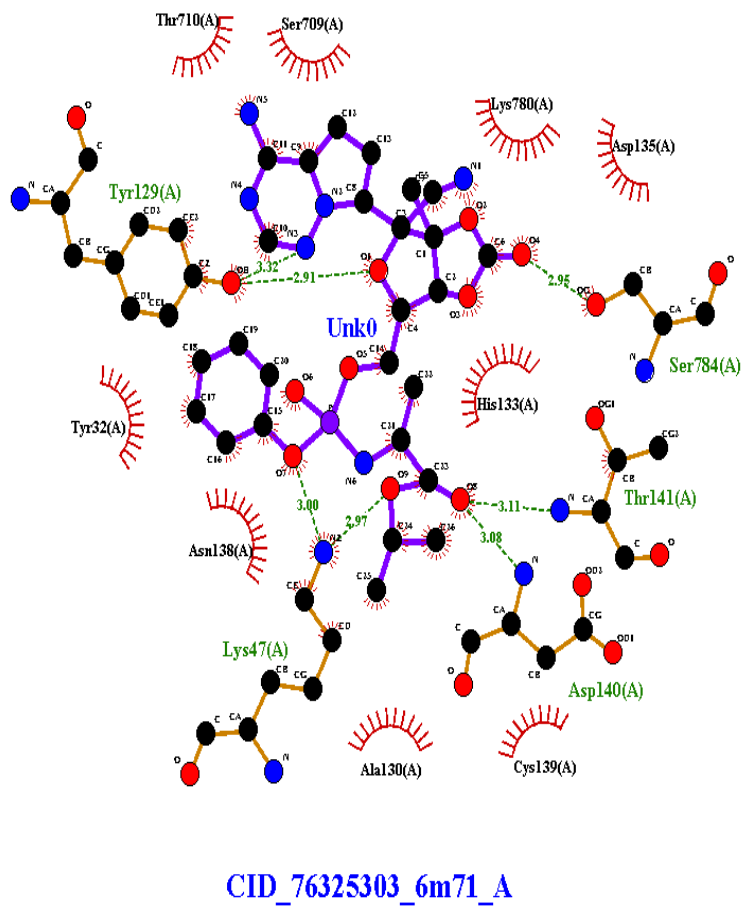

Table 4: Using LigPlus+, the active site amino acids for these Ligand Molecule on Chain A -nsp12

\begin{tabular}{|l|l|l|}
\hline S.No & Ligands & $\begin{array}{l}\text { Active Site } \\
\text { Amino Acids }\end{array}$ \\
\hline 1 & $\begin{array}{l}\text { CHEMBL3120791 } \\
\text { (CID76325303) }\end{array}$ & $\begin{array}{l}\text { Lys47, Ser784, } \\
\text { Tyr129, His133 }\end{array}$ \\
\hline 2 & $\begin{array}{l}\text { SCHEMBL20733228 } \\
\text { (CID137490593) }\end{array}$ & $\begin{array}{l}\text { Lys 47, Ser709, } \\
\text { Thr141, His133 }\end{array}$ \\
\hline & $\begin{array}{l}\text { SCHEMBL20762917 } \\
\text { (CID137517260) }\end{array}$ & $\begin{array}{l}\text { Lys47, Ser784, } \\
\text { Tyr129, His133, } \\
\text { Ser709, Asn781 }\end{array}$ \\
\hline 3 & $\begin{array}{l}\text { CID90055716 } \\
\text { (Uprifosbuvir) }\end{array}$ & $\begin{array}{l}\text { Tyr129, Ser709, } \\
\text { Thr141 }\end{array}$ \\
\hline
\end{tabular}

CHEMBL3120791 is Remdesivir analogue, where as SCHEMBL20733228, and SCHEMBL20762917 are Uprifosbuvir analogue. They are potential inhibitors, and have previously shown antiviral activity in wet lab analysis in case of HCV virus [27]. We believe efficacy of these potential inhibitors can be tested against SARS Coronavirus $2-$ RdRP. The conformational stability of this molecule can be tested using Molecular Dynamic simulation. Further experimental data in wet-lab will provide evidence of the efficacy of these molecules. Structural difference are shown in Fig. 2 and Fig. 3

Fig. 2. Structural difference of high binding energy molecules with Remdesivir and CHEMBL3120791.

2. (a) Remdesivir (CID121304016)

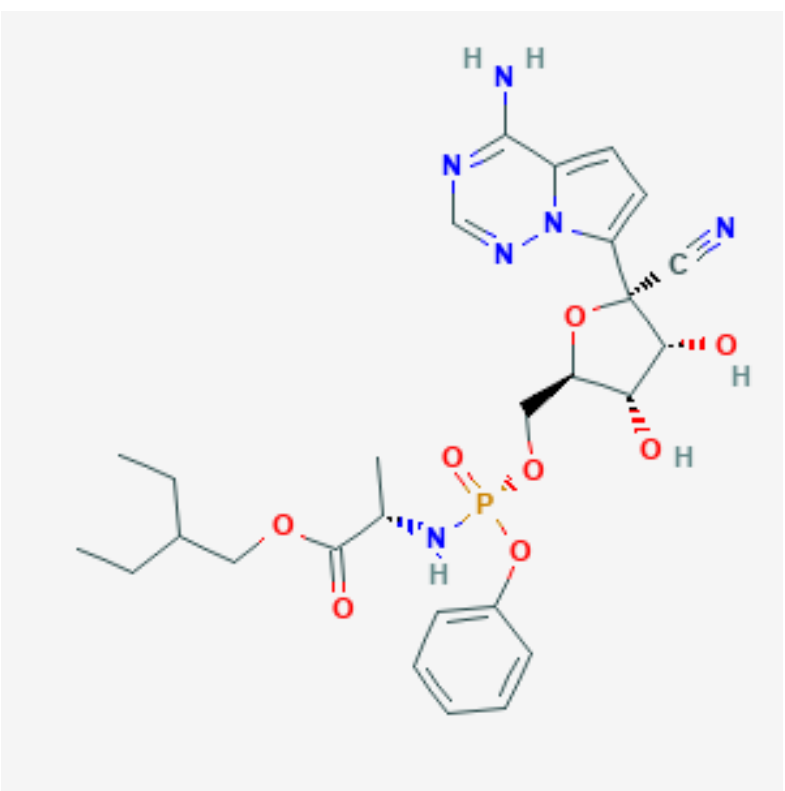

2. (b) CHEMBL3120791

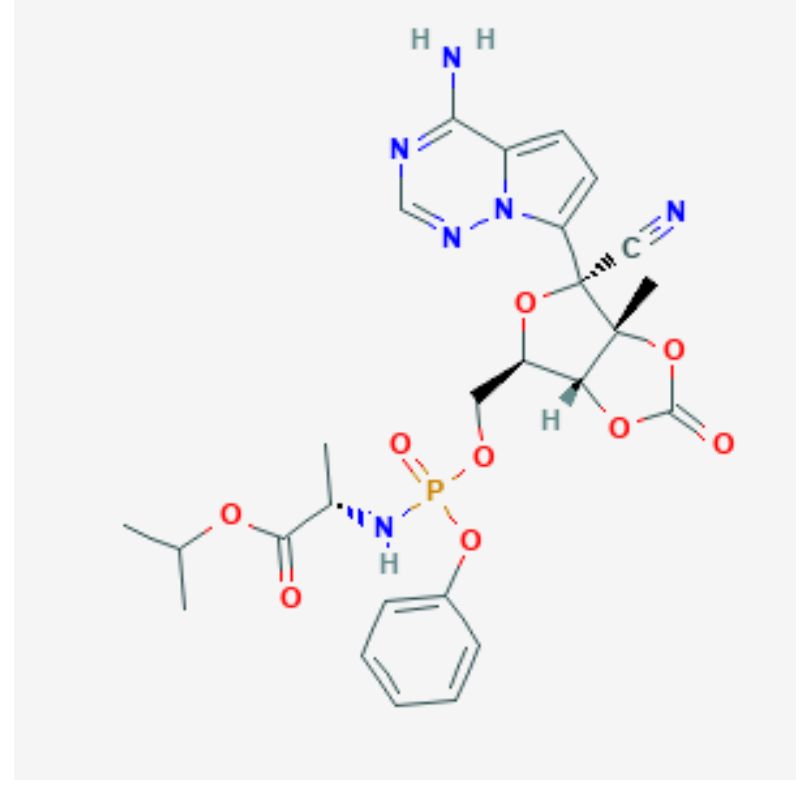

Fig 3. Structural differences with Uprofosbuvir, SCHEMBL20762917 and SCHEMBL20733228 


\section{International Journal of Engineering Applied Sciences and Technology, 2020 Vol. 5, Issue 3, ISSN No. 2455-2143, Pages 474-481 \\ Published Online July 2020 in IJEAST (http://www.ijeast.com)}

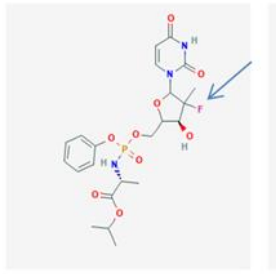

SCHEMBL20733228 (CID_137490593)

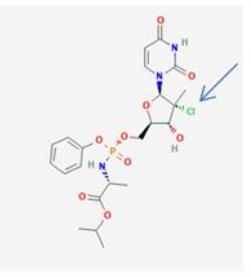

Uprifosbuvir (CID_90055716)

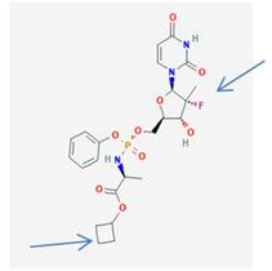

SCHEMBL20762917 (CID_137517260)
The hepatitis $\mathrm{C}$ virus (HCV) is a small, enveloped, single-stranded, positive-sense RNA virus which is similar to Coronaviruses which have positive-sense, single-stranded RNA genome [38]. The inhibitor identified in this study has been tested against $\mathrm{HCV}$ virus [27].

We also investigated binding efficacy of these identified inhibitors against SARS spike protein for this we used pdb files $2 \mathrm{GHV}$ (SARS spike protein receptor binding domain) and 5XLR (SARS CoV spike glycoprotein). In addition, 1P9U which is coronavirus main proteinase was also evaluated. The compounds identified and reported here also showed better binding affinity towards these proteins. (Table 5)

Table 5: Binding Energy with other than RNA dependent RNA polymerase: PDB Id's 2GHV, 5XLR, 1P9U. Binding Energy in (Kcal/mol).

\begin{tabular}{|l|l|l|l|l|}
\hline S.No & Ligand & 2GHV & $\begin{array}{l}5 \mathrm{XL} \\
\mathrm{R}\end{array}$ & $\begin{array}{l}\text { 1P9 } \\
\mathrm{U}\end{array}$ \\
\hline 1 & CHEMBL3120791 & -7.4 & -8.8 & -9.5 \\
\hline 2 & SCHEMBL20733228 & -6.4 & -8.5 & -8.5 \\
\hline 3 & SCHEMBL20762917 & -7.0 & -8.2 & -8.8 \\
\hline 5 & Uprifosbuvir & -6.9 & -7.8 & -8.5 \\
\hline 5 & Remdesivir & -6.5 & -2.8 & -9.3 \\
\hline
\end{tabular}

\section{CONCLUSION}

From these studies we can conclude that analogue of Remdesivir such as CHEMBL3120791 and analogue of Uprifosbuvir such as SCHEMBL20762917, SCHEMBL20733228 can be potentially used not only in the prevention of viral RNA replication but also against virus receptor binding reaction. If the spike protein is inhibited from binding human ACE2 receptor viral load can be decreased. The main proteinase of SARS virus also was inhibited with these compounds. The inhibitors identified here can be tested further in human clinical trials as they exhibit better binding than Remdesivir and Uprifosbuvir.

\section{REFERENCES}

[1] W.H.O. (2020). WHO Coronavirus Disease (COVID-19) Dashboard, https://covid19.who.int/

[2] Malik Y. A. (2020). Properties of Coronavirus and SARSCoV-2. The Malaysian journal of pathology, 42(1), 3-11.

[3] Miranda, J., Mattar, S., Gonzalez, M., Hoyos-López, R., Aleman, A., \& Aponte, J. (2019). First report of Culex flavivirus infection from Culex coronator (Diptera: Culicidae), Colombia. Virology journal, 16(1), 1. https://doi.org/10.1186/s12985-018-1108-2

[4] van Regenmortel MHV, Fauquet CM, Bishop DHL, Carstens EB, Estes MK, Lemon SM, et al. Coronaviridae. In: MHV v R, Fauquet CM, DHL B, Carstens EB, Estes MK, Lemon SM, et al., editors., Virus taxonomy: Classification and nomenclature of viruses Seventh report of the International Committee on Taxonomy of Viruses. San Diego: Academic Press; 200: 835-49. ISBN 0123702003

[5] da Costa, V. G., Moreli, M. L., \& Saivish, M. V. (2020). The emergence of SARS, MERS and novel SARS-2 coronaviruses in the 21st century. Archives of virology, 165(7), 1517-1526. https://doi.org/10.1007/s00705-02004628-0

[6] Venkataraman, S., Prasad, B., \& Selvarajan, R. (2018). RNA Dependent RNA Polymerases: Insights from Structure, Function and Evolution. Viruses, 10(2), 76. https://doi.org/10.3390/v10020076

[7] Mittal, L., Kumari, A., Suri, C., Bhattacharya, S., \& Asthana, S. (2020). Insights into structural dynamics of allosteric binding sites in HCV RNA-dependent RNA polymerase. Journal of biomolecular structure \& dynamics, 38(6), $1612-1625$. https://doi.org/10.1080/07391102.2019.1614480

[8] Yin, W., Mao, C., Luan, X., Shen, D. D., Shen, Q., Su, H., Wang, X., Zhou, F., Zhao, W., Gao, M., Chang, S., Xie, Y. C., Tian, G., Jiang, H. W., Tao, S. C., Shen, J., Jiang, Y., Jiang, H., Xu, Y., Zhang, S., ... Xu, H. E. (2020). Structural basis for inhibition of the RNA-dependent RNA polymerase from SARS-CoV-2 by remdesivir. Science (New York, N.Y.), 368(6498),

1499-1504.

https://doi.org/10.1126/science.abc1560

[9] Zhang, Leili \& Ruhong, Zhou. (2020). Binding Mechanism of Remdesivir to SARS-CoV-2 RNA Dependent RNA Polymerase. 10.20944/preprints202003.0267.v1.

[10] Eastman, R. T., Roth, J. S., Brimacombe, K. R., Simeonov, A., Shen, M., Patnaik, S., \& Hall, M. D. (2020). Remdesivir: A Review of Its Discovery and Development Leading to Emergency Use Authorization for Treatment of COVID-19. ACS central science, 6(5), 672-683. https://doi.org/10.1021/acscentsci.0c00489 


\section{International Journal of Engineering Applied Sciences and Technology, 2020 Vol. 5, Issue 3, ISSN No. 2455-2143, Pages 474-481 \\ Published Online July 2020 in IJEAST (http://www.ijeast.com)}

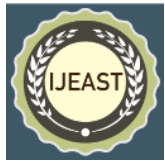

[11] Green, N., Ott, R. D., Isaacs, R. J., \& Fang, H. (2008). Cell-based Assays to Identify Inhibitors of Viral Disease. Expert opinion on drug discovery, 3(6), 671-676. https://doi.org/10.1517/17460441.3.6.671

[12] Zhou P, Yang XL, Wang XG, et al. A pneumonia outbreak associated with a new coronavirus of probable bat origin. Nature. 2020;579(7798):270-273. doi:10.1038/s41586020-2012-7

[13] Gheblawi, M., Wang, K., Viveiros, A., Nguyen, Q., Zhong, J. C., Turner, A. J., Raizada, M. K., Grant, M. B., \& Oudit, G. Y. (2020). Angiotensin-Converting Enzyme 2: SARS-CoV-2 Receptor and Regulator of the ReninAngiotensin System: Celebrating the 20th Anniversary of the Discovery of ACE2. Circulation research, 126(10), 14561474. https://doi.org/10.1161/CIRCRESAHA.120.317015

[14] Wrapp, D., Wang, N., Corbett, K. S., Goldsmith, J. A., Hsieh, C. L., Abiona, O., Graham, B. S., \& McLellan, J. S. (2020). Cryo-EM structure of the 2019-nCoV spike in the prefusion conformation. Science (New York, N.Y.), 367(6483),

https://doi.org/10.1126/science.abb2507

[15] Xu, X., Chen, P., Wang, J., Feng, J., Zhou, H., Li, X., Zhong, W., \& Hao, P. (2020). Evolution of the novel coronavirus from the ongoing Wuhan outbreak and modeling of its spike protein for risk of human transmission. Science China. Life sciences, 63(3), 457-460. https://doi.org/10.1007/s11427-020-1637-5

[16] Allen, Charles \& Arjona, Sterling \& Santerre, Maryline \& sawaya, bassel. (2020). Potential use of RNA-dependent RNA polymerase (RdRp) inhibitor against COVID-19 infection. 10.31219/osf.io/cgb25.

[17] Zhang, L., \& Zhou, R. (2020). Structural Basis of the Potential Binding Mechanism of Remdesivir to SARS-CoV-2 RNA-Dependent RNA Polymerase. The journal of physical chemistry. B, acs.jpcb.0c04198. Advance online publication. https://doi.org/10.1021/acs.jpcb.0c04198

[18] Anand, Kanchan \& Yang, Haitao \& Bartlam, Mark \& Rao, Zihe \& Hilgenfeld, Rolf. (2006). Coronavirus main proteinase: target for antiviral drug therapy. 10.1007/3-76437339-3_9.

[19] Xue, X., Yu, H., Yang, H., Xue, F., Wu, Z., Shen, W., Li, J., Zhou, Z., Ding, Y., Zhao, Q., Zhang, X. C., Liao, M., Bartlam, M., \& Rao, Z. (2008). Structures of two coronavirus main proteases: implications for substrate binding and antiviral drug design. Journal of virology, 82(5), 2515-2527. https://doi.org/10.1128/JVI.02114-07

[20] Anand, K., Ziebuhr, J., Wadhwani, P., Mesters, J. R., \& Hilgenfeld, R. (2003). Coronavirus main proteinase (3CLpro) structure: basis for design of anti-SARS drugs. Science (New York, $\quad$ N.Y.), 300(5626), 1763-1767. https://doi.org/10.1126/science.1085658

[21] Gao, Y., Yan, L., Huang, Y., Liu, F., Zhao, Y., Cao, L., Wang, T., Sun, Q., Ming, Z., Zhang, L., Ge, J., Zheng, L., Zhang, Y., Wang, H., Zhu, Y., Zhu, C., Hu, T., Hua, T., Zhang, B., Yang, X., ... Rao, Z. (2020). Structure of the RNA- dependent RNA polymerase from COVID-19 virus. Science (New York, N.Y.), 368(6492), 779-782. https://doi.org/10.1126/science.abb7498

[22] PDB ID: $6 \mathrm{~m} 71$ Available: https://www.rcsb.org/structure/6M71

[23] Kirchdoerfer, R. N., \& Ward, A. B. (2019). Structure of the SARS-CoV nsp12 polymerase bound to nsp7 and nsp8 cofactors. Nature communications, 10(1), 2342. https://doi.org/10.1038/s41467-019-10280-3

[24] Kim, S., Chen, J., Cheng, T., Gindulyte, A., He, J., He, S., Li, Q., Shoemaker, B. A., Thiessen, P. A., Yu, B., Zaslavsky, L., Zhang, J., \& Bolton, E. E. (2019). PubChem 2019 update: improved access to chemical data. Nucleic acids research, 47(D1),

D1102-D1109. https://doi.org/10.1093/nar/gky1033

[25] Crotty, S., Maag, D., Arnold, J. J., Zhong, W., Lau, J. Y., Hong, Z., Andino, R., \& Cameron, C. E. (2000). The broadspectrum antiviral ribonucleoside ribavirin is an RNA virus mutagen. Nature medicine, 6(12), 1375-1379. https://doi.org/10.1038/82191

[26] Powdrill, Megan \& Bernatchez, Jean \& Götte, Matthias. (2010). Inhibitors of the hepatitis C virus RNA-dependent RNA polymerase NS5B. Viruses. 2. 2169-95. 10.3390/v2102169.

[27] Lawitz, E., Buti, M., Vierling, J. M., Almasio, P. L., Bruno, S., Ruane, P. J., Hassanein, T. I., Muellhaupt, B., Pearlman, B., Jancoriene, L., Gao, W., Huang, H. C., Shepherd, A., Tannenbaum, B., Fernsler, D., Li, J. J., Grandhi, A., Liu, H., Su, F. H., Wan, S., ... Yoshida, E. M. (2017). Safety and efficacy of a fixed-dose combination regimen of grazoprevir, ruzasvir, and uprifosbuvir with or without ribavirin in participants with and without cirrhosis with chronic hepatitis $\mathrm{C}$ virus genotype 1,2 , or 3 infection (CCREST-1 and C-CREST-2, part B): two randomised, phase 2, open-label trials. The lancet. Gastroenterology \& hepatology, 2(11), 814-823. https://doi.org/10.1016/S24681253(17)30163-2

[28] Takehara, T., Chayama, K., Kurosaki, M., Yatsuhashi, H., Tanaka, Y., Hiramatsu, N., Sakamoto, N., Asahina, Y., Nozaki, A., Nakano, T., Hagiwara, Y., Shimizu, H., Yoshida, H., Huang, Y., Biermer, M., Vijgen, L., \& Hayashi, N. (2020). JNJ-4178 (adafosbuvir, odalasvir, and simeprevir) in Japanese patients with chronic hepatitis $\mathrm{C}$ virus genotype 1 or 2 infection with or without compensated cirrhosis: the Phase IIa OMEGA-3 study. Journal of gastroenterology, 55(6), 640652. https://doi.org/10.1007/s00535-020-01672-0

[29] Morris, G. M., Huey, R., Lindstrom, W., Sanner, M. F., Belew, R. K., Goodsell, D. S. and Olson, A. J. (2009) Autodock4 and AutoDockTools4: automated docking with selective receptor flexiblity. J. Computational Chemistry 2009, 16: 2785-91.

[30] Trott, O., \& Olson, A. J. (2010). AutoDock Vina: improving the speed and accuracy of docking with a new scoring function, efficient optimization, and multithreading. 


\section{International Journal of Engineering Applied Sciences and Technology, 2020 Vol. 5, Issue 3, ISSN No. 2455-2143, Pages 474-481 \\ Published Online July 2020 in IJEAST (http://www.ijeast.com)}

Journal of computational chemistry, 31(2), 455-461. https://doi.org/10.1002/jcc. 21334

[31] Dallakyan, S., \& Olson, A. J. (2015). Small-molecule library screening by docking with PyRx. Methods in molecular biology (Clifton, N.J.), 1263, 243-250. https://doi.org/10.1007/978-1-4939-2269-7_19

[32] Hwang, W. C., Lin, Y., Santelli, E., Sui, J., Jaroszewski, L., Stec, B., Farzan, M., Marasco, W. A., \& Liddington, R. C. (2006). Structural basis of neutralization by a human antisevere acute respiratory syndrome spike protein antibody, 80R. The Journal of biological chemistry, 281(45), 34610 34616. https://doi.org/10.1074/jbc.M603275200

[33] Gui, M., Song, W., Zhou, H., Xu, J., Chen, S., Xiang, Y., \& Wang, X. (2017). Cryo-electron microscopy structures of the SARS-CoV spike glycoprotein reveal a prerequisite conformational state for receptor binding. Cell research, 27(1), 119-129. https://doi.org/10.1038/cr.2016.152

[34] Cho, A., Zhang, L., Xu, J., Lee, R., Butler, T., Metobo, S., Aktoudianakis, V., Lew, W., Ye, H., Clarke, M., Doerffler, E., Byun, D., Wang, T., Babusis, D., Carey, A. C., German, P., Sauer, D., Zhong, W., Rossi, S., Fenaux, M., ... Kim, C. U. (2014). Discovery of the first C-nucleoside HCV polymerase inhibitor (GS-6620) with demonstrated antiviral response in $\mathrm{HCV}$ infected patients. Journal of medicinal chemistry, 57(5), 1812-1825. https://doi.org/10.1021/jm400201a

[35] National Center for Biotechnology Information (2020). PubChem Patent View for Patent US2019046552. Retrieved August 2, $2020 \quad$ from https://pubchem.ncbi.nlm.nih.gov/patent/US2019046552.

[36] Laskowski, R. A., \& Swindells, M. B. (2011). LigPlot+: multiple ligand-protein interaction diagrams for drug discovery. Journal of chemical information and modeling, 51(10), 2778-2786. https://doi.org/10.1021/ci200227u

[37] Wallace, A. C., Laskowski, R. A., \& Thornton, J. M. (1995). LIGPLOT: a program to generate schematic diagrams of protein-ligand interactions. Protein engineering, 8(2), 127 134. https://doi.org/10.1093/protein/8.2.127

[38] Kim, C. W., \& Chang, K. M. (2013). Hepatitis C virus: virology and life cycle. Clinical and molecular hepatology, 19(1), 17-25. https://doi.org/10.3350/cmh.2013.19.1.17

[39] National Center for Biotechnology Information (2020). PubChem Compound Summary for CID 5064. Retrieved August 2, $2020 \quad$ from https://pubchem.ncbi.nlm.nih.gov/compound/5064.

[40] National Center for Biotechnology Information (2020). PubChem Compound Summary for CID 37542, Ribavirin. Retrieved August 2, 2020 from https://pubchem.ncbi.nlm.nih.gov/compound/Ribavirin.

[41] National Center for Biotechnology Information (2020). PubChem Compound Summary for CID 100252, Ribavirin monophosphate. Retrieved August 2, 2020 from https://pubchem.ncbi.nlm.nih.gov/compound/Ribavirinmonophosphate.
[42] National Center for Biotechnology Information (2020). PubChem Compound Summary for CID 122108, Ribavirin 5'triphosphate. Retrieved August 2, 2020 from https://pubchem.ncbi.nlm.nih.gov/compound/Ribavirin-5_triphosphate.

[43] National Center for Biotechnology Information (2020). PubChem Compound Summary for CID 124970, Ribavirin 5'diphosphate. Retrieved August 2, 2020 from https://pubchem.ncbi.nlm.nih.gov/compound/Ribavirin-5_diphosphate.

[44] National Center for Biotechnology Information (2020). PubChem Compound Summary for CID 129235, Ribavirin 5'sulfamate. Retrieved August 2, 2020 from https://pubchem.ncbi.nlm.nih.gov/compound/Ribavirin-5_sulfamate.

[45] National Center for Biotechnology Information (2020). PubChem Compound Summary for CID 362949. Retrieved August 2, $2020 \quad$ from https://pubchem.ncbi.nlm.nih.gov/compound/362949.

[46] National Center for Biotechnology Information (2020). PubChem Compound Summary for CID 451448, Taribavirin. Retrieved August 2, 2020 from https://pubchem.ncbi.nlm.nih.gov/compound/Taribavirin.

[47] National Center for Biotechnology Information (2020). PubChem Compound Summary for CID 451949. Retrieved $\begin{array}{lll}\text { August 2, } 2020 \quad \text { from } & \text { 2, }\end{array}$ https://pubchem.ncbi.nlm.nih.gov/compound/451949.

[48] National Center for Biotechnology Information (2020). PubChem Compound Summary for CID 452722, 3'Deoxyribavirin. Retrieved August 2, 2020 from https://pubchem.ncbi.nlm.nih.gov/compound/3_-

Deoxyribavirin.

[49] National Center for Biotechnology Information (2020). PubChem Compound Summary for CID 460516, Levovirin. Retrieved August 2, 2020 from https://pubchem.ncbi.nlm.nih.gov/compound/Levovirin.

[50] National Center for Biotechnology Information (2020). PubChem Compound Summary for CID 6713992. Retrieved August 2, $2020 \quad$ from https://pubchem.ncbi.nlm.nih.gov/compound/6713992.

[51] National Center for Biotechnology Information (2020). PubChem Compound Summary for CID 10220469. Retrieved August 2, $2020 \quad$ from https://pubchem.ncbi.nlm.nih.gov/compound/10220469.

[52] National Center for Biotechnology Information (2020). PubChem Compound Summary for CID 11436477, alphaRibavirin. Retrieved August 2, 2020 from https://pubchem.ncbi.nlm.nih.gov/compound/alpha-Ribavirin. [53] National Center for Biotechnology Information (2020). PubChem Compound Summary for CID 40629571. Retrieved $\begin{array}{lll}\text { August 2, } 2020 \quad \text { from } & \text { 2, }\end{array}$ https://pubchem.ncbi.nlm.nih.gov/compound/40629571.

[54] National Center for Biotechnology Information (2020). PubChem Compound Summary for CID 54759694. Retrieved 


\section{International Journal of Engineering Applied Sciences and Technology, 2020 Vol. 5, Issue 3, ISSN No. 2455-2143, Pages 474-481 \\ Published Online July 2020 in IJEAST (http://www.ijeast.com)}

August 2, 2020 from https://pubchem.ncbi.nlm.nih.gov/compound/54759694.

[55] National Center for Biotechnology Information (2020). PubChem Compound Summary for CID 70989848. Retrieved August 2, $2020 \quad$ from https://pubchem.ncbi.nlm.nih.gov/compound/70989848.

[56] National Center for Biotechnology Information (2020). PubChem Compound Summary for CID 76325303. Retrieved August 2, $2020 \quad$ from https://pubchem.ncbi.nlm.nih.gov/compound/76325303.

[57]. National Center for Biotechnology Information (2020). PubChem Compound Summary for CID 90055716, Uprifosbuvir. Retrieved August 2, 2020 from https://pubchem.ncbi.nlm.nih.gov/compound/Uprifosbuvir.

[58] National Center for Biotechnology Information (2020). PubChem Compound Summary for CID 118596336, Adafosbuvir. Retrieved August 2, 2020 from https://pubchem.ncbi.nlm.nih.gov/compound/Adafosbuvir.

[59] National Center for Biotechnology Information (2020). PubChem Compound Summary for CID 121304016, Remdesivir. Retrieved August 2, 2020 from https://pubchem.ncbi.nlm.nih.gov/compound/Remdesivir.

[60] National Center for Biotechnology Information (2020). PubChem Compound Summary for CID 137465280. Retrieved August 2, 2020 from https://pubchem.ncbi.nlm.nih.gov/compound/137465280.

[61] National Center for Biotechnology Information (2020). PubChem Compound Summary for CID 137490591. Retrieved August 2, 2020 from https://pubchem.ncbi.nlm.nih.gov/compound/137490591.

[62] National Center for Biotechnology Information (2020). PubChem Compound Summary for CID 137490593. Retrieved August 2, 2020 from https://pubchem.ncbi.nlm.nih.gov/compound/137490593.

[63] National Center for Biotechnology Information (2020). PubChem Compound Summary for CID 137509756. Retrieved August 2, 2020 from https://pubchem.ncbi.nlm.nih.gov/compound/137509756.

[64] National Center for Biotechnology Information (2020). PubChem Compound Summary for CID 137517260. Retrieved August 2, 2020 from https://pubchem.ncbi.nlm.nih.gov/compound/137517260.

[65] National Center for Biotechnology Information (2020). PubChem Compound Summary for CID 137517361. Retrieved August 2, 2020 from https://pubchem.ncbi.nlm.nih.gov/compound/137517361.

[66] National Center for Biotechnology Information (2020). PubChem Compound Summary for CID 45375808, Sofosbuvir. Retrieved August 2, 2020 from https://pubchem.ncbi.nlm.nih.gov/compound/psi-7977.

[67] National Center for Biotechnology Information (2020). PubChem Compound Summary for CID 6440764, Thymectacin. Retrieved August 2, 2020 from https://pubchem.ncbi.nlm.nih.gov/compound/Thymectacin.
[68] National Center for Biotechnology Information (2020). PubChem Compound Summary for CID 3652, Hydroxychloroquine. Retrieved August 2, 2020 from https://pubchem.ncbi.nlm.nih.gov/compound/Hydroxychloroq uine.

[69] National Center for Biotechnology Information (2020). PubChem Compound Summary for CID 71826, Cletoquine. Retrieved August 2, 2020 from https://pubchem.ncbi.nlm.nih.gov/compound/Cletoquine.

[70] National Center for Biotechnology Information (2020). PubChem Compound Summary for CID 5988, Sucrose. Retrieved August 2, 2020 from https://pubchem.ncbi.nlm.nih.gov/compound/Sucrose.

[71] National Center for Biotechnology Information (2020). PubChem Compound Summary for CID 439186, D-(+)Maltose. Retrieved August 2, 2020 from https://pubchem.ncbi.nlm.nih.gov/compound/D-_-Maltose.

[72] National Center for Biotechnology Information (2020). PubChem Compound Summary for CID 192225, Amino sugar U 7. Retrieved August 2, 2020 from https://pubchem.ncbi.nlm.nih.gov/compound/Amino-sugar-U7.

\section{ACKNOWLEDGMENT}

This paper and the research behind it would not have been possible without the exceptional support of my friends Dr. Pankaj Goyal and Dr. Shyamsri Biswas for all scientific discussions and drafting of the manuscript. I also sincere thanks to my friends from the School of Biotechnology, Banaras Hindu University, Varanasi, U.P, India. 